\title{
ADDRESSING DEPRESSION AND ANXIETY AMONG NEW FATHERS
}

Abstract

- Fathers are unintentionally marginalised by perinatal health services and by social practices surrounding new babies.

- There is increasing recognition that fathers' depression and anxiety in the perinatal period can have serious consequences for the family.

- We propose utlizing father-specific materials by general practitioners and allied health workers and extending the current male-only sessions in antenatal education to all health regions.

The birth of his first child marks one of the most profound changes a man may undergo, transforming his standing in the community, his most intimate relationships and his identity. Yet, he may come to the moment of his infant's birth naively, unprepared for the speed of the changes taking place and unaware of the range and depth of the demands which he will face. From the point of view of the new baby, it will be important to have a father who is ready to provide care and sustenance and to support the mother in her new role; but it will also be important to have a father who has the mental and emotional resources to form a secure and nourishing relationship. Supporting those who need assistance in preparing for fatherhood may arguably be seen as a responsibility of public health care yet new fathers are unlikely to access existing support services and even a cursory scan of perinatal health services reveals that few services are designed to address father's specific needs $(1,2)$.

\section{Scenario - the usual arrangements}

From the combined knowledge of the authors derived from 20 years in family general practice and many years experience interviewing, researching and facilitating educational and therapy groups for fathers, the following scenario has been constructed to capture important elements of the situation of new fathers

When Michelle and Anthony attend Michelle's GP after the positive pregnancy test Anthony expresses his support but asks few questions. When asked about the couples' intentions for pregnancy care Anthony's quick glance toward Michelle flags his uncertainty. For the next visits Michelle attends the clinic alone. Anthony does participate in the ultrasound consultation and he joins in when asked during the antenatal classes but he accepts that the emphasis throughout is appropriately on the mother and a successful birth. During the birth he wonders if he is in the way and is grateful in the end to have a healthy mother and baby. Post birth, when the home visiting nurse arrives, Anthony goes to make coffee and misses most of the discussion. His return to work precludes him attending the checkups for mother and baby at the doctors.

Anthony's minimal role with health professionals is mirrored at home and in social settings. Michelle reads the books, brochures and magazines and tells Anthony about popular names, baby development, and the dangers of SIDS. Anthony is affectionately ribbed by workmates about sleep deprivation and nappy changing and although one of his mates has just become a father Anthony has little chance to learn about the business of 
fathering. Social time with the new baby is dominated by eager mothers or girlfriends there are few opportunities for Anthony to try out "holding a new baby" without drawing attention to himself.

In a bygone era the fathers' lack of engagement, and his relegation to "anonymous helper" by the health services may have been appropriate both from the perspective of social mores and from our understanding of child development. Today, a central community expectation of fathers is that they will nurture and care for their offspring. Belatedly, the scientific study of fathers is also shifting to explore the impact of fathers on the development of infants and young children and health services are being questioned about the matri-focal bias in their clinics and programs.

\section{Fathers' mental health}

In the last few years the importance of the woman's emotional health during the transition to parenthood has been increasingly recognized to the extent that routine psychosocial screening has been argued for, or implemented, in several sites in Australia (3-5). There is now the start of a debate as to the need to provide a similar service for men $(6,2)$ given what we know about the mental health of men during this transition. This knowledge can be summarized as follows:

When a new mother is distressed there is a reasonable likelihood that the father may also be distressed $(7,8)$; in $50 \%$ of couples where the mother is depressed, so too is the father (9). In addition, the rate of diagnosed anxiety or depression disorders in men at 6 weeks postpartum is around $2-5 \%(10,11)$ and a recent Australian study found that fathers experience the antenatal period as more stressful than the postnatal period (12). Mood disorders among fathers have consequences for their offspring. Father's postnatal depression may exacerbate the effects of mother's depression on child development and children with two depressed parents are at an elevated risk of deficits in social, psychological and cognitive domains $(13,14)$. Well fathers, on the other hand, have been shown to have a buffering effect against the detrimental concomitants of a mother's depression on the infant's well-being $(15,16)$.

Father's depression alone can also negatively affect infant development. After controlling for mothers depression and later paternal depression, having a father who was depressed at eight weeks postpartum was found to double the risk of behaviour and emotional problems in children at 3.5 years of age (17). These findings, which mirror the welldocumented impact of maternal postnatal depression on infants and children, strongly suggest that when assessing the health of a new family the man's emotional health should be considered alongside that of the woman's. Hence the start of the debate as to the benefits to the community if health services considered not only the woman's emotional health during the transition to parenthood, but also the man's $(6,2)$.

\section{What could health services do?}

Economic and cultural factors may make it impossible for new fathers to accompany their partners to every health service visit. More could be done however to address 
father's need for support when he does attend with his partner and specific information on his role as a father could be directed to men in the perinatal period.

\section{Antenatal Education}

Most couples attend preparation for childbirth classes. In recent times services have piloted the inclusion of father-specific sessions usually facilitated by male health workers. In one region where father-only sessions have been established as part of standard antenatal care an evaluation study found that fathers valued the time to discuss the father's role with other fathers and strongly endorsed the value of the session (18). In addition, a randomised control trial that included expectant fathers in a preparation for parenthood session that focused on postnatal emotional adjustment for the couple has been conducted (19). This study found that the emotional adjustment for the woman was significantly enhanced. Such programmes could be expanded to become part of routine care across all health services, providing a more active focus on the partnership between mothers and fathers as well as supporting the father's role.

\section{In the clinic}

Males in the 20-35 age group rarely seek medical advice without acute symptoms, and are reluctant to seek advice regarding emotional health issues $(20,21)$. The regular contact of mothers through the antenatal clinic, General Practitioners and Early Childhood Clinics during the perinatal period, provides an opportunity to supply information on parenting from a father's perspective, to assist new fathers to distinguish between mood disorders and the normal stress occasioned by a new baby and to make them aware of existing support services. Clinicians could provide, either directly to the attending father or to his partner, information and advice for expectant or new fathers along with a self-assessment tool such as the Edinburgh Depression Scale (22). The Edinburgh Depression Scale, which has been validated for English-speaking fathers postnatally (23), is already widely used in antenatal and postnatal assessment of mothers and is available as a 'Self Test' on the Black Dog Institute website (24) though it is important to note that different cut-off scores to those validated for women need to be used when screening for a mood or anxiety disorder (23). Advice about the common stresses experienced by new fathers, the use of the EDS as an aid to seeking appropriate help, from his General Practitioner for example, could be included, as well as a letter/brochure outlining the importance of a father's well-being to himself and his family. Pamphlets describing father's role in infant well being and providing brief guides and checklists have been produced by various health and education bodies and many are available at low cost. Input to fathers via the clinic could also be supported by remote services such as the dedicated telephone help line for men in the perinatal period being piloted in the UK (1).

\section{Conclusion}

Services within Australia are matching (and sometimes leading) those in other countries with respect to assessing and providing support for psychosocial health in expectant and new mothers. Given the impact of both parents' emotional health on each other, and their family, it is timely to now consider ways that similar services can be provided for expectant and new fathers. We have put forward some suggestions regarding such male- 
oriented services, and would hope that whatever services are offered are evaluated so that a sound evidence-base can be built-up which will assist clinical services in the future.

1. Fletcher R, Silberberg S, Galloway D. New fathers' postbirth views of antenatal classes: Satisfaction, benefits, and knowledge of family services. The Journal of Perinatal Education 2004; 13: 18-26.

2. Currid TJ. Psychological issues surrounding paternal perinatal mental health. Nurs Times 2005; 101: 40-42.

3. Buist AE, Barnett BEW, Milgrom J. et al. To screen or not to screen - that is the question in perinatal depression. Med J Aust. 2002; 177: S101-S105.

4. Matthey S, White T, Phillips J. et al. Acceptability of routine antenatal psychosocial assessments to women from English and non-English speaking backgrounds. Arch Women Ment Health. 2005; 8: 171- 180.

5. Webster J, Linnane J, Roberts J. IDentify, Educate and Alert (IDEA) trial: an intervention to reduce postnatal depression. BJOG. 2003; 110: 842-846.

6. Buist A, Morse CA, Durkin S. Men's adjustment to fatherhood: implications for obstetric health care. J Obstet Gynecol Neonatal Nurs. 2003; 32: 172-180.

7. Tammentie T, Tarkka MT, Astedt-Kurki P. Family dynamics and postnatal depression. J Psychiatr Ment Health Nurs. 2004; 11: 141-149.

8. Goodman JH. Paternal postpartum depression, its relationship to maternal postpartum depression, and implications for family health. J Adv Nurs. 2004; 45: 26-35.

9. Harvey I, McGrath G. Psychiatric morbidity in spouses of women admitted to a mother and baby unit. Br J Psychiatry. 1988; 152: 506-510.

10. Matthey S, Barnett B, Ungerer J. et al. Paternal and maternal depressed mood during the transition to parenthood 2000. Journal of Affective Disorders; 60: 75-85.

11. Matthey S, Barnett B, Howie P. et al. Diagnosing postpartum depression in mothers and fathers: whatever happened to anxiety? Journal of Affective Disorders 2003; 74: 139-147.

12. Condon JT, Boyce P, Corkindale CJ. The First-Time Fathers Study: a prospective study of the mental health and wellbeing of men during the transition to parenthood. Aust N Z J Psychiatry. 2004; 38: 56-64.

13. Burke L. The impact of maternal depression on familial relationships Int Rev Psychiatry. 2003; 15: 243-255.

14. Carro MG, Grant KE, Gotlib IH. et al. Postpartum depression and child development: An investigation of mothers and fathers as sources of risk and resilience. Development \& Psychopathology 1993; 5: 567-579.

15. Albertsson-Karlgren U, Graff M, Nettelbladt P. Mental disease postpartum and parent-infant interactionevaluation of videotaped session. Child Abuse Review 2001; 10: 5-17.

16. Edhborg M, Lundh W, Seimyr L. et al. The parent-child relationship in the context of maternal depressive mood. Arch Women Ment Health. 2003; 6: 211-216.

17. Ramchandani P, Stein A, Evans J. et al. Paternal depression in the postnatal period and child development: a prospective population study. Lancet 2005; 365: 2201-2205.

18. Friedewald M, Fletcher R, Fairbairn H. All-male discussion forums for expectant fathers: evaluation of a model The Journal of Perinatal Education 2005; 14: 8-18.

19. Matthey S, Kavanagh DJ, Howie P. et al. Prevention of Postnatal Distress or Depression: An evaluation of an intervention at Preparation for Parenthood classes. J Affect Disord. 2004; 79: 113-126.

20. Aoun S, Palmer M, Newby R. Gender issues in psychosocial morbidity in general practice. Australian Journal of Social Issues 1998; 33: 335-353. 
21. Brownhill S, Wilhelm K, Barclay L. et al. 'Big build': hidden depression in men. Aust N Z J Psychiatry. 2005; 39: 921-931.

22. Cox J, Holden J. Perinatal mental health: a guide to the Edinburgh Postnatal Depression Scale. London: Gaskell Press, 2003.

23. Matthey S, Barnett B, Kavanagh et al. Validation of the Edinburgh Postnatal Depression Scale for men, and comparison of item endorsement with their partners. Journal of Affective Disorders 2001; 64:175-183.

24. Depression and Bipolar Disorder Information Australia - Black Dog Institute [Homepage on the Internet].Available from:

http://www.blackdoginstitute.org.au/depression/inpregnancy/documents/Edinburghdownloadablepublicversio $\underline{\text { n.pdf }}$ Downloaded 30/6/06 